\title{
Survey on Cyber Attacks
}

\author{
Roshni Bhandari \\ Assistant Professor \\ Computer Department \\ S. S Agrawal Institute of \\ Engineering \& Technology \\ Navsari
}

\author{
Rathod Swapnil \\ Student \\ Computer Department \\ S.S Agrawal Institute of \\ Engineering \& Technology \\ Navsari
}

\author{
Tailor Vishwa \\ Student \\ Computer Department \\ S.S Agrawal Institute of \\ Engineering \& Technology \\ Navsari
}

\section{Patel Jaydip \\ Student \\ Computer Department \\ S.S Agrawal Institute of Engineering \& Technology Navsari}

\begin{abstract}
It is not possible to make your business wider without using communication. Communication plays an important role in business. Nowadays computer system having internet makes it easy for communication at any level. There are advantages and disadvantages of any object. E-Communication may have different disadvantages. I.e. theft of data, personal information leaking, etc. The present study is an attempt to reveal the varied cyber-attack techniques adopted by cyber criminals to target the selected banks in India where spoofing, brute force attack are found positively correlated with public and private sector banks. Further, the research shows a positive correlation between Intruder Detection and cyber-attacks, i.e., online identity theft, hacking, malicious code, DOS attack and credit card/ATM frauds as well as online identity theft, DOS attack \& credit card/ATM fraud are found positively correlated with System Monitoring.
\end{abstract}

\section{General Terms}

Victim, Anomalies, System monitoring, Hacker.

\section{Keywords}

Identity Theft, Intruder Detection, Spyware.

\section{INTRODUCTION}

A cyber-attack is deliberate exploitation of computer systems, technology-dependent enterprises and networks. Cybercriminals use malicious code to alter computer code, logic or data, resulting in disruptive consequences that can compromise data and lead to cybercrimes, such as information and identify theft.

Their objectives include [1]:

- Gaining or attempting to gain.

- Unauthorized access to a computer system or its data.

- Unwanted interruption or denial of service attacks including the take down of entire web sites.

- Installation of viruses or malware - that is malicious code on a computer system.

- Changes to the characteristics of a computer system, hardware firmware or software without the owner's permission, instruction or consent.

- Unauthorized use of a computer system for processing or storing data.

- Inappropriate use of computer system by employees or former employees.

\author{
Davara Sagar \\ Student \\ Computer Department \\ S.S Agrawal Institute of Engineering \& Technology \\ Navsari
}

Table 1. Table of History of Cyber Crime

History records

\begin{tabular}{|c|c|}
\hline Year & History records \\
& \\
\hline \multirow{1}{*}{$1988-$} & 1989 saw the creation of the first \\
& computer worm, which was crafted by \\
Robert Morris to test the size of the & internet. Unfortunately, the \\
manipulating virus spread aggressively, \\
essentially terminating the internet. The \\
impact of the initial worm was not on \\
the same level of devastation that could \\
be created by harmful malware today. \\
However, it was the first of many to \\
come and shaped how viruses were \\
managed for decades. Furthermore, this \\
meant businesses had to invest in the \\
first defensive security products, such as \\
firewalls. It was cyber security's first \\
step to counter the threats. [2]
\end{tabular}




\begin{tabular}{|c|c|}
\hline & foreign intruders. [3] \\
\hline $\begin{array}{l}\text { April } \\
2007\end{array}$ & $\begin{array}{c}\text { Estonian government networks were } \\
\text { harassed by a denial of service attack by } \\
\text { unknown foreign intruders, following the } \\
\text { country's spat with Russia over the removal } \\
\text { of a war memorial. Some government online } \\
\text { services were temporarily disrupted and } \\
\text { online banking was halted. The attacks were } \\
\text { more like cyber riots than crippling attacks, } \\
\text { and the Estonians responded well, launching } \\
\text { some services within hours or - at most - } \\
\text { days. [3] }\end{array}$ \\
\hline $\begin{array}{l}\text { June } \\
2007\end{array}$ & $\begin{array}{l}\text { The US Secretary of Defense's unclassified } \\
\text { email account was hacked by unknown } \\
\text { foreign intruders as part of a larger series of } \\
\text { attacks to access and exploit the Pentagon's } \\
\text { networks. [3] }\end{array}$ \\
\hline $\begin{array}{c}\text { October } \\
-2007\end{array}$ & $\begin{array}{l}\text { China's Ministry of State Security said that } \\
\text { foreign hackers, which it claimed } 42 \% \text { came } \\
\text { from Taiwan and } 25 \% \text { from the US, had } \\
\text { been stealing information from Chinese key } \\
\text { areas. In 2006, when the China Aerospace } \\
\text { Science \& Industry Corporation (CASIC) } \\
\text { intranet network was surveyed, spywares } \\
\text { were found in the computers of classified } \\
\text { departments and corporate leaders. [3] }\end{array}$ \\
\hline $\begin{array}{l}\text { August } \\
2008\end{array}$ & $\begin{array}{l}\text { Computer networks in Georgia were hacked } \\
\text { by unknown foreign intruders around the } \\
\text { time that the country was in conflict with } \\
\text { Russia. Graffiti appeared on Georgian } \\
\text { government websites. There was little or no } \\
\text { disruption of services but the hacks did } \\
\text { put political pressure on the Georgian } \\
\text { government and appeared to be coordinated } \\
\text { with Russian military actions. [3] }\end{array}$ \\
\hline $\begin{array}{c}\text { January } \\
2009\end{array}$ & $\begin{array}{l}\text { Hackers attacked Israel's internet } \\
\text { infrastructure during the January } 2009 \\
\text { military offensive in the Gaza Strip. The } \\
\text { attack, which focused on government } \\
\text { websites, was executed by at least } 5,000,000 \\
\text { computers. Israeli officials believed the } \\
\text { attack was carried out by a criminal } \\
\text { organization based in a former Soviet state, } \\
\text { and paid for by Hamas or Hezbollah. [3] }\end{array}$ \\
\hline $\begin{array}{c}\text { January } \\
2010\end{array}$ & $\begin{array}{l}\text { A group named the "Iranian Cyber Army" } \\
\text { disrupted the service of the popular Chinese } \\
\text { search engine Baidu. Users were redirected } \\
\text { to a page showing an Iranian political } \\
\text { message. The same "Iranian Cyber Army" } \\
\text { had hacked into Twitter the previous } \\
\text { December, with a similar message. [3] }\end{array}$ \\
\hline $\begin{array}{c}\text { October } \\
2010\end{array}$ & $\begin{array}{l}\text { Subnet, a complex piece of malware } \\
\text { designed to interfere with Siemens industrial } \\
\text { control systems, was discovered in Iran, } \\
\text { Indonesia, and elsewhere, leading to } \\
\text { speculation that it was a government cyber } \\
\text { weapon aimed at the Iranian nuclear } \\
\text { programmer. [3] }\end{array}$ \\
\hline $\begin{array}{c}\text { January } \\
2011\end{array}$ & $\begin{array}{c}\text { The Canadian government reported a major } \\
\text { cyber-attack against its agencies, including } \\
\text { Defiance Research and Development } \\
\text { Canada, a research agency for Canada's }\end{array}$ \\
\hline
\end{tabular}

\begin{tabular}{|c|c|}
\hline & $\begin{array}{l}\text { Department of National Defiance. The attack } \\
\text { forced the Finance Department and Treasury } \\
\text { Board, Canada's main economic agencies, to } \\
\text { disconnect from the Internet. [3] }\end{array}$ \\
\hline 2014 & $\begin{array}{l}\text { During } 2014, \text { there were massive recent } \\
\text { data breaches of Target and Sony. } \\
\text { Target booked } \$ 162 \text { million in expenses } \\
\text { throughout } 2013 \text { and } 2014 \text { related to } \\
\text { the data breach, in which hackers broke } \\
\text { into the company's network to } \\
\text { access credit card information and } \\
\text { other customer data, affecting some } 70 \\
\text { million customers. Moreover, Sony's } \\
\text { data breach was inflicted by North } \\
\text { Korea, which shows that you don't have } \\
\text { to be part of a criminal organization to } \\
\text { cause this damage. [2] }\end{array}$ \\
\hline 2017 & $\begin{array}{l}\text { This year saw the outbreak of } \\
\text { the "biggest ransom ware outbreak". The } \\
\text { attack saw the likes of the NHS and } \\
\text { FedEx dismantled. Spanish } \\
\text { telecommunications company } \\
\text { Telephonic was among many targets in } \\
\text { the country along with German railway } \\
\text { operator Deutsche Bahn. [2] }\end{array}$ \\
\hline
\end{tabular}

\section{TYPES OF CYBER ATTACK}

\subsection{Malware Attack}

Malware is known as any computer code created for causing malice. Although one may not have known the technical definition of malware, chances are the user has fallen victim of some type of malware. Malware is capable of infecting computer systems slowing or shutting them down and steal valuable information. Malware continues to grow limitlessly along with cyber-attacks and is a popular tool in cyberattacks. Another problem with malware is the contagious abilities of it. Malware is able to quickly spread across the web since due to its ability to be a small file with capabilities of infecting whole file systems. Malware can cause more harm the longer it exists in the home user's system. For this reason, it is important to protect against, detect, and eliminate malware from home user's computers.

\section{Types of Malware [5]}

\subsubsection{Spyware}

Spyware is the most common form of malware for stealing valuable information. Spyware simply does as the name implies and spies on any information home users enter in the computer or browser through various methods.

\subsubsection{Viruses}

Computer viruses are similar to biological viruses in terms of survival. Biological viruses need to feed off of a host through the host's cells to live. On the other hand, computer virus, files in the computers system are essentially to the "cell" inside of the computer host. Depending on the severity of the virus, infection can spread to system files effectively slowing or even damaging the computer entirely.

\subsubsection{Worms}

Worms, although much less common can be more of a threat due to their ability to live on their own. Worms work similar to ways a virus works except worms do not need a host to 
live. This is dangerous because without the necessity of a host, infection can spread much quicker. Worms can also be harder to detect due to the fact that no host is needed.

\section{Restriction [6]}

- Movie \& picture download by the safe website.

- Install the antivirus.

- Install the firewall.

- Give the password to our important files.

\subsection{DDOS Attacks [5]}

A Distributed Denial of Service attack uses internet traffic to overwhelm servers forcing a shut-down of the system or a slowing of services. This increased traffic denies access and limits usability to legitimate users or systems. Not only is the number of DDOS attacks increasing, but so too is the complexity.

\section{Restricting [7]}

The best way to Restriction an additional breach is to keep your system as secure as possible with regular software updates, online security monitoring and monitoring your data flow to identify any unusual or increasing threats in traffic before they become a problem.

\subsection{Malvertising [7]}

A way to compromise your computer with malicious code that is downloaded to your system when you click on an affected ad. Cyber attacker upload display ad to different sites using an ad network. These ads are then distributed to sites that match certain keywords and search criteria. Once a user clicks on one of these ads, some types of Malware will be downloaded.

\section{Restriction}

The best way to Restriction falling victim to advertising is to use common sense. Any ad that promises riches, free computers or cruises to the Bahamas is probably too good to be true, and therefore could be hiding Malware.

\subsection{Man in the Middle (MITM) Attacks [9]}

In this type of attacks hacker break down original connection between server and client and make a duplicate connection among them. From this connection hacker can get details and data from both sides, from client or server and can monitoring the transaction between client and server.

\section{Restriction [7]}

The best way to Restriction them is to only use encrypted wireless access points that use WPA security or greater. If you need to connect to a website, make sure it uses an HTTPS connection or, for better security, consider investing in a virtual private network (VPN).

\subsection{Rogue Software [7]}

Malware that masquerades as legitimate and necessary security software that will keep your system safe. Rogue security software designers make pop-up windows and alerts that look legitimate. These alerts advise the user to download security software, agree to terms or update their current system in an effort to stay protected.
The best defense is to keep an updated firewall. Make sure that you have a working one in your office that protect you and your employee from these types of attacks.

\subsection{Cross Site Scripting (XSS) Attack [10]}

XSS attacks use third-party web resources to run scripts in the victim's web browser or scriptable application. Specifically, the attacker injects a payload with malicious JavaScript into a website's database when the victim requests a page from the website, the website transmits the page, with the attacker's payload as part of the HTML body, to the victim's browser, which executes the malicious script.

\section{Restricting [8]}

To reduce the chances of your site becoming a victim of an XSS attack, it's essential that any Web application is developed using some form of security development lifecycle (SDL). Their aim is to reduce the number of security-related design and coding errors in an application, and reduce the severity of any errors that remain undetected. This applies to any data received by the application data, cookies, emails, files or images even if the data is from users who have logged into their account and authenticated themselves.

\subsection{Password Attacks [4]}

As computer users, passwords serve as essentially keys to all our private information. When the password is lost, it must be retest quickly to Restriction the risk of theft. For such reasons, it is important to understand how hackers can essentially steal passwords from unsuspecting victims. Some methods of password attacks include: password guessing, password resetting, and password capturing. Password guessing is predicting possible password combinations until the right combination is found. Although this method may seem to take unreasonable lengths of time to accomplish, software's can shorten the process. Since many people still use common passwords such as their birthdays or names for passwords; the process is much shorter than many may think. Another threat is reusing passwords, essentially allowing hackers to access multiple accounts using that one password. Password resetting is not a very common method of password attacks. It requires the hacker to get access in to the file system of the operating system before anything can be done. However, once inside, hackers can modify and crack system files which contain the user's password. Finally, password capturing uses malware which allows hackers to unsuspectingly track all of user's keystrokes. This effectively allows hackers to get the user's passwords right away.

\section{Restriction [7]}

Strong password is the only way to safeguard against password attacks. This means using a combination of upper and lower-case letters, symbols and number and having at least eight characters or more.

\subsection{Phishing [9]}

It is a request which sent via emails or other messages to victim and ask the victim to click on the link and enter required data.

\section{Restriction [8]}

Communicate personal information only via phone or secure web sites. In fact: Do not click on links, download files or open attachments in emails from unknown senders.

\section{Restriction}




\section{CYBER SECURITY TOOLS}

\subsection{Nmap [12]}

Map your network and ports with the number one port scanning tool. Nmap now features powerful NSE scripts that can detect vulnerabilities, misconfiguration and security related information around network services. After you have nmap installed be sure to look at the features of the included ncat - its net cat on steroids.

\subsection{Wireshark[12]}

View traffic in as much detail as you want. Use Wireshark to follow network streams and find problems. Tcpdump and Tshark are command line alternatives. Wireshark runs on Windows, Linux, FreeBSD or OSX based systems.

\subsection{Nessus [13]}

Nessus allows scans for the following types of vulnerabilities:

- Vulnerabilities that allow a remote hacker to control or access sensitive data on a system.

- Misconfiguration (e.g. open mail relay, missing patches, etc.).

- Default passwords, a few common passwords, and blank/absent passwords on some system accounts. Nessus can also call Hydra (an external tool) to launch a dictionary attack.

- Denials of service against the TCP/IP stack by using mangled packets.

\subsection{Snort [12]}

Snort is a real time traffic analysis and packet logging tool. It can be thought of as a traditional IDS, with detection performed by matching signatures. The project is now managed by Cisco who use the technology in its range of Source Fire appliances. An alternative project is the Suricata system that is a fork of the original Snort source.

\subsection{Safe Browsing [4]}

One should be weary of using websites that have no security measures in place for personal information. Most websites will show links to the security certificate if information is encrypted. Home users can simply check for such certificates to assist in deciding whether the organization can be trusted with information.

Here are some tips:

- Disable the use of remembering passwords for sites in all browsers.

- Disable the use of remembering what entered in form in all browsers.

- Make sure browser setting is set to clear data when browser is closed.

- Block pop-ups for all the browsers.

- $\quad$ Set the internet zone security level.

- Do not open unknown e-mail attachments or respond to unknown e-mails.

- Password protects all devices that are connected to the internet.
- Do not respond to online requests for asking personal identifiable information.

\subsection{Os Query[12]}

Monitors a host for changes and is built to be performing from the ground up. This project is cross platform and was started by the Facebook Security Team. It is a powerful agent that can be run on all your systems (Windows, Linux or OSX) providing detailed visibility into anomalies and security related events.

\section{CONCLUSION}

Though not all people are victims to cybercrimes, they are still at risk. Crimes by computer vary, and they don't always occur behind the computer, but they are executed by computer. Generally, hacker's identity is ranged between 12 years to 67 years. The hacker could live three continents away from its victim, and they wouldn't even know they were being hacked. Crimes done behind the computer are the $21 \mathrm{st}$ century's problem. With the technology increasing, criminals neither have to rob banks, nor do they have to be outside in order to commit any crime. They have everything they need on their Device. Their weapons aren't guns anymore; they attack with keyboard, cursors and passwords.

\section{REFERENCES}

[1] Farhat, Vince, McCarthy, Bridget \& Raysman, Richard (Holland \& Knight LLP), History of cyber attacks, Published by Practical Law Company on its PLC Intellectual Property and Technology web services.

[2] Energi Group, Fresh01, 2001, History of cyber attacks.

[3] Essay.ws/ History of cyber crime.

[4] Hayder Teymourlouei, 2015, awareness and Restrictionions for home user, World Academy of Science Engineering \& Technology.

[5] Coburn, Aw Daffron J, Smith A, Bordeau J, Leverret E, Sweeney S, Harvey T, 2018, Cyber Risk Lookout, University of Cambridge.

[6] Joshua, Indentitytheftkiller, 2018, phishing scam

[7] Jeff Melnick, Netwrix, 2018, 10 most common cyber attacks.

[8] Megan Sullivan, Quickbooks, 2018, types of cyber attacks.

[9] Amarujala Hindi Newspaper, Malware Attack

[10] Neil Dupaul, Veracode, 2012, Common Malware Types.

[11] Checkpoint, 2018, Security Reports.

[12] Waste/awareness and Restrictionion.

[13] Abdullah Saad H. Alqahtani, Mohsin Iftikhar, Semanticsscholar, 2013, Restrictionion Tools 